\title{
A Study via Interviews of the Chinese Bouyei College Learners' EFL Classroom Anxiety
} Arousals

\author{
Jianhua Wei \\ The School of Foreign Languages, the Guangdong Institute of Petrochemical Industry, Maoming City 525000, China
}

\begin{abstract}
The aim of the present study is to investigate anxiety arousals attributive to the Chinese Bouyei college learners' EFL classroom anxiety through semi-structured individual interviews of twenty-five informants from five colleges in Guizhou Province, China. The findings illustrate nine types of the Bouyei participants' college EFL classroom anxiety causal factors reported, i.e., Low FL Ability, Teacher's Problem in Teaching, Negative Attitudes towards English Class, Societal Interferences, Lack of Confidence, Fear of Failing English Class, Fear of Losing Face, Lack of Preparation, and Sense of Inferiority, which half supported the results of the rotated component matrix of factor analysis for the FLCACSQ conducted with 320 subjects in the present researchers' previous study in use of a closed-ended questionnaire. In addition, the research findings were discussed followed by some implications in the conclusion.
\end{abstract}

Index Terms - Chinese, Bouyei, EFL learners at college, anxiety arousals, implications

\section{INTRODUCTION}

Anxiety is considered as a response of cognitive affection characterized by physiological arousal (indicative of sympathetic nervous system activation) and apprehension regarding a potentially negative outcome that the individual perceives as impending, as well as an unpleasant emotional state or condition which is characterized by subjective feelings of tension, apprehension, and worry, and by activation or arousal of the automatic nervous system (Leary, 1983; Spielberger, 1972; cited by Wei, 2013). In such a state relating to emotion, a person usually gets nervous when s/he feels $\mathrm{him} / \mathrm{herself}$ as a failure and seems guilty due to the factors that stop him/her from reaching a successful target, or the obstacles that s/he cannot conquer.

According to the theory of the "Affective Filter" (Krashen, 1982), anxiety in the foreign language (FL) context is reckoned as a negative factor that leads to a FL learner's less responses to language input, and an effort to impart more particular messages than those in a setting without anxiety. FL classroom anxiety is hence described by Horwitz, Horwitz and Cope (1986; cited by Wei, 2013) as a situation-specific anxiety originating from the particular learning process of a FL, especially when learners lowly appraise their communicative abilities in that language. FL classroom anxiety is then thought likely to bring about poor outcomes, as claimed by Gregersen (2005). This has been proved in the studies (Chen, 2002; Liu, 2006b; Tan, 2009; cited by Wei, 2013) among Chinese college learners as subjects, although learners' proficiency vary a great deal due to individual differences, linguistic differences, cultural differences, the examination-oriented education system and so on (Wei, 2012). As stressed by Wei (2012), FL classroom anxiety can negatively affect the Chinese learners' course grades and interest in English, intentions to continue their English learning, and their CET-4 scores; and irrelevant information input is usually what the Chinese undergraduate college students with high anxiety are more engaged in, and hence results in their less opportunities to receive meaningful information for their English learning. Due to the high level of the "Affective Filter", researchers (Spielberge, 1966; Horwitz, 2001; MacIntyre \& Gardner, 1991; Young, 1991; Yamashiro \& McLaughlin, 2001) have pointed out that higher levels of anxiety are likely to bring about lower levels of proficiency in English learning. Classroom anxiety is actually a source of poor English learning in both individuals and situation as an unquestionable arousal (Horwitz, 2001; Gobel \& Matsuda, 2003; Chen, 2002; Liu, 2006b; Tan, 2009). The quantitative study in use of Horwitz's FLCAS (Foreign Language Classroom Anxiety Scale) (1986, p.129) administered by Wei (2012) has showed that medium levels of overall classroom anxiety $(M=3.10, S D=.68)$, as well as of communication anxiety, test anxiety, and fear of negative evaluation, were experienced by Chinese Bouyei college EFL learners.

Concerning the arousals of EFL classroom anxiety, previous studies have demonstrated various causal factors, like Language Competence (Onwuegbuzie et al., 1999; Aida, 1994; Tasee, 2009; Dewaele et al., 2008; cited by Wei, 2012), Self-Confidence (Cheng et al., 1999; Cheng, 2002; Matsuda \& Gobel, 2004; cited by Wei, 2012), Self-Esteem (Laine, 1987; Rubio, 2007; Wang, 2009), Introversion and Extraversion (Liu et al., 2010; Dewaele, 2002), Learners' Beliefs on FL Learning (Ohata, 2005; Dai \& Wang, 2002; Bao, 2011), Instructors' Beliefs on FL Learning/Teaching (Tanveer, 2007; Zhang, 2009; Huang, 2008; cited by Wei, 2012), Instructor-Learner Interactions (Tsui, 1996; Liu, 2006a; cited by Wei, 2012), Classroom Procedure (Jackson, 2002; William \& Andrade, 2008; cited by Wei, 2012), Language Testing (Chapell et al., 2005; Chen, 2007; Onwuegbuzie, 1995; cited by Wei, 2012), and Social Status and 
Self-Identity (McCroskey, 1980; Chick, 1985; Zhang et al., 2003; Tanveer, 2007; cited by Wei, 2012). These factors were found closely associated with anxiety arousals by some scholars, whereas in some studies the results were a bit different, and even contradictory. One thing is for sure that based on the abovementioned statements, these factors are also closely interrelated with each other and most of them are not likely to take place separately. However, some factors might "vary" according to different settings with different subjects as well as how studies are conducted.

Nevertheless, investigations into the anxiety of minority ethnic learners are still not so common in China, especially in the remote mountainous areas. Whether these abovementioned factors are responsible for the existence of the Bouyei college learner' EFL classroom anxiety is still not very well perceived and hence needs further research. The research hence aims to explore such learners' possible EFL classroom anxiety arousals, as in the research question (RQ), "What are the main causal factors of the Bouyei college EFL learners in China?", that is assumed to arise from the learner's beliefs, the language learning process, or from the situation or social environment s/he is a part of, etc., which were investigated in present researcher's previous quantitative study via questionnaire (Also see Wei, 2012). The second most important aim is to make some suggestions as strategies for other researchers and ELF instructors for the alleviation of the learners' anxiety in EFL.

\section{ReSEARCH METHODOLOGY}

\section{A. Participants}

The 25 1st- and 2nd-year Chinese Bouyei students, the same subjects also mentioned previously in one of Wei's (2012) studies, participated the investigation. They were randomly selected from various classes at each of the following five colleges - the South Guizhou Teachers College for Ethnic Groups, the South Guizhou Vocational College for Ethnic Groups, the South Guizhou Medial Science College for Ethnic Groups, the Xinyi Teachers College for Ethnic Groups, and the Southwest Guizhou Vocational College for Ethnic Groups. Most of the interviewees came from the countryside as the native speakers of the Bouyei language.

\section{B. Instrument}

The tool for the data collection of the present study was semi-structured individual interviews with 10 questions translated into Chinese (See Wei, 2012). The rationale for the use of semi-structured interviews is that it can provide detailed, supplementary access to things that cannot be directly or completely observed, such as feelings, thoughts, intentions, or beliefs, especially the learners' anxiety causal factors, that the close-ended questionnaires are not bound to cover. Despite questionnaires which can draw out rich responses from the informants about their EFL classroom anxiety, it is also helpful to use interviews in the present study in order to achieve more, important information as a supplement through various elicitations (Wei, 2013). At the same time, the present study also utilizes percentage to ascertain the frequency of the interviewees' reported anxiety.

\section{Data Collection}

The main areas of the interviews as well as ten refined questions for the interviews had been worked out in advance by the researcher. The researcher formally talked face to face with the interviewees in order to collect data from them in a harmonious setting.

\section{Data Analyses}

The researcher listened to the audio-recordings of the individual interviews and thereafter comprehensively transcribed what the subjects stated in relevant sections according to the similarities of the context or situation from which the EFL classroom anxiety were resulted (Wei, 2013). Then the researcher reduced data by coding, synthesis, etc. repetitiously based on the "open coding" and "axial coding" techniques proposed by Paunch (2005, see Wei, 2013) and Strauss and Corbin's (1998; see Wei, 2013). Percentage of the anxiety arousals reported by the informants was also taken to illustrate the frequency of anxiety causes related.

\section{FINDINGS}

All possible anxiety causes were included in the results from the interviews with detailed information in order to have a general view of the informants' anxiety arousals. Each of the informants was labeled with a code according to the time order of being interviewed. For example, a student who was the first one to be interviewed was marked as ST1 (Also see Wei, 2013). Through the data of the interviews, the present research has found nine types of anxiety causal factors. Under each of these factors are related respects, along with the informants' utterances. What follows are the inventory of relative arousals and the presentation of necessary examples of the informants' anxiety causal factors reported, followed by the person-time and percentage of the 25 interviewees who shared the same categories and aspects, the way as also stated in one of Wei's previous studies (2013).

\section{(1) Low FL Ability (LFLA) (45) (180\%)}

Low FL Ability was what the Bouyei students mostly expressed as a factor that resulted in their classroom anxiety. This factor covers four aspects of worries in both receptive and productive abilities, which include: "inability in listening", "inability in speaking", "inability in reading", and "inability in writing". The following are what they 
reported:

- LFLA 5.1: Inability in listening (11) (44\%)

A certain number of the interviewees said that they felt nervous when not hearing very well what the teacher was requiring them to do in class. Some claimed being unable to understand a thing the teacher was saying. They reported that they sometimes found it harder to understand the Chinese English teacher than the native speaker, because some Chinese teacher spoke very fast while the native speaker seemed to be considerate about their comprehensive ability and then spoke more slowly. For example:

ST23: ... By the way, I feel nervous while I cannot hear very well what the teacher is requiring us to do in English class.

ST7: ...I'm very anxious in English class, especially, in English listening, because we never received such training at high school.

ST12: ...I can be very anxious when not understanding the teacher speaking too fast, or when I do not prepare.

- LFLA 5.2: Inability in speaking (15) $(60 \%)$

Many of the interviewees reported that they were anxious when not able to answer the teacher's questions. They felt nervous when they forgot some words in bigger groups of discussions or before the class and did not know so well about how to organize words in proper order to make a sentence. For example:

ST9: ...As my mother always says, I am cowardice in doing things before others. Actually, I'm in fear of being lower in ability in class, and my face turns red when I cannot answer the teacher's questions.

ST22: ...I feel embarrassed when not knowing what to say in group discussions and...I'm not called to the Bb because my English is poor. If I am called to the Bb, I will write or speak nothing but stand there at a loss...

ST7: ...We learn English which is not needed in everyday communication. So, I'm usually afraid of being laughed at due to my inability to communicate with others when I do not know how to express my mind.

- LFLA 5.3 Inability in reading (11) (44\%)

Some interviewees reported that they were anxious when not completely understanding the reading materials although they were not so bad at English in class. Some of them reported that their vocabulary was small which was really a handicap to them in reading and would be nervous when required to read loudly in class. For example:

ST11: ...I can feel anxious when I don't understand completely what I am reading although I believe that I'm one of the good students in English class.

ST13: ...I am so anxious that I usually stayed where I am while reading a new text although the text seems not so difficult...

ST23: ...I would be anxious when encountering more new words in reading and will not understand what is being read....

- LFLA 5.4 Inability in writing (8) $(24 \%)$

Inability in writing was also reported as an aspect of the factor Low FL Ability, similar to the aspect associated with speaking. As some of them claimed, they were worried if they were wasting other classmates' time when writing on the $\mathrm{Bb}$ because they might do it very slowly for not knowing how to organize the sentences. For example:

ST4: ...I can be less nervous while writing on the Bb, but worried about wasting others' time.

ST22: ...I'm not called to the Bb because my English is poor. If I am called to the Bb, I will write or speak nothing but stand there at a loss...

ST19:...I fear worried while not understanding the class, especially, grammar. My grammar is poor, so I don't know how to express my idea in English.

(2) Teacher's Problem in Teaching (TPT) (20) (80\%)

Teacher's Problem in Teaching (Wei, 2012) is a factor that some Bouyei participants very much complained as what worried them at the same time. It concludes four aspects: "unequal treatment", "talking too much", "humdrum teaching styles", and "emotion inappropriately shown" as follows:

- TPT 8.1: Unequal treatment $(9)(36 \%)$

Some Bouyei students complained that the teacher never asked them to the $\mathrm{Bb}$ or answer questions because their English might be not satisfactory. On the contrary, those students whose English was good in class were given more opportunities to speak. For example:

ST 5: ...The teacher usually asks others to the Bb but not me. Although my English is not so good, sometimes I am well prepared and also willing to show what I can in class.

ST25:...My pronunciation is not so good, so the teacher seldom asks me to read the text in class.

ST10: ...The students better at spoken English are given more chances to answer questions.

\section{- TPT 8.2: Talking too much in class}

It was also complained by some of the interviewees that the teacher talked too much in class and hence providing no opportunities for them to practice their English speaking. They were willing to play a role in pair work and group discussions. For example:

ST17:...The teacher talks too much and gives us less chance to speak. We need more opportunities to go to the Bb.

ST13: ...We have no group discussions given by some Chinese teachers, but the foreign teacher is different. The teacher talks and talks and we don' know what she is talking about. 
- TPT 8.3: Humdrum teaching styles (6) (24\%)

This aspect involves what some of the students reported as the teacher's teaching styles that did not attract their interest in class. They complained that some English teacher seemed neither so well prepared nor so energetic in class and their teaching styles were humdrum without change. What they reported is calling on the teacher's innovative teaching approaches in fact. For example:

ST8: ...Some English teachers are not so energetic in class, unlike the foreign teacher who even gives awards to us for our small progress.

ST9: ...I don't like English class because it is quite boring and I am afraid have forgotten what I have learned before....

ST19:...Some teachers can make English lessons very interesting...I like those teachers' lessons which are very interesting...However, some other teachers seem to make do with their lessons... and we feel a bit bored.

ST3: ...The English teacher's class is so boring for me. He should use new teaching approaches like the native speaker to stimulate our interest.

- TPT 8.4: Emotion inappropriately shown (5) (20\%)

Some interviewees mentioned that they did not like the teacher who was so serious and was likely to lose temper once s/he did not receive a rapid response from the students. They felt relaxed if the teacher smiled and liked to use humorous words in class. For example:

ST23: ... The teacher seems not so kind and friendly. She should have more smiles and not that serious...She should have more humorous words in class and make jokes in class...

ST6: ...Some teacher seems not so kind and is likely to loose temper in class when some of us cannot answer questions as expected...

ST11: ...I agree that the teacher should be more encouraging and not loose temper in any case. Unfortunately, our teacher is very mean in praising anybody, but often shows how unhappy she is.

ST15: ...Some teacher seems not so well prepared and is a bit moody in class. That is not welcome by the students and makes us worried very much.

(3) Negative Attitudes towards English Class (NAEC) (16) (64\%)

The factor Negative Attitudes towards English Class (Wei, 2012) refers mainly to what the students negatively consider English class is like. It consists of three aspects including "more anxiety in English class than in other classes", "no interest in English class", and "nothing learned in English class", which are as follows:

- NAEC 2.1: More anxiety in English class than in other classes (7) (28\%)

It was said by some Bouyei students that they had more anxiety in English class than in other classes (Wei, 2012) for their inability in English language. Also a language, as reported, Chinese is their second language, but easier to learn, because they found less pressure in learning Chinese with many people speaking the language around everyday since the primary school. For example:

ST14: ...Learning Chinese is easier than learning English and we started learning English when very young and had more time speaking Chinese with other people around.

ST25: ...I feel bad in English class...It seems as if I were an idiot in English class, ... although I feel much relaxed and confident in other courses.

ST3: ... I have more anxiety in English and less in Chinese, because English is for test and Chinese not really for test. Chinese is something we use to communicate with people around every day. ... We have people to talk with in Chinese everyday.

- NAEC 2.2: No interest in English class (6) (24\%)

Some of the interviewees reported that they feel terrible in class because they had no interest in it at all. The biggest anxiety was that although they showed no interest in English, they had to go to English class for fear of being punished by the school or the teacher. For example:

ST2: ...I sit in English class, but always think about other things....and I don't even know what to worry for being long terrible at English learning.

ST1: ... Once I sit in English class, Ifeel worried. I'm not interested in it.

ST4: ...Though I show no interest in English, I know I have to go to English class. The reason is that if I'm absent for English class too many times, I fear to be punished by the school.

ST3: ...I often feel like going out from English class... because I find it too hard, and too boring, to tell you the true.

- NAEC 2.3. Nothing learned in English class (3) (12\%)

It was declared by some interviewees that learning English was a waste of time because they had learned nothing in the course and it was too late for them to learn it well. For example:

ST11: ... When going to English class, I have the feeling of being forced to do something I don't like, ....because I find I have learned nothing in it. ... Why should I waste my time in English class? ...Anyhow, I have to attend the class no matter how much I dislike it.

ST5: ... I like English anyway, but I'm not so good at it. So I feel I will not learn it as well as I learn other courses...I know it might be too late for me to learn it now. I fear I am wasting my time.

(4) Societal Interferences (SI) (13) (52\%) 
Societal Interferences in the present study refers to what is originated from the society outside class and distracts the students' concentrations away from normal classroom activities in English learning (Wei, 2012). This factor is reported by some students as responsible for their anxiety in English class. It includes "pressure from CET and TEM" and "concerns about other tests" as follows:

- SI 9.1: Pressure from CET and TEM (8) (32\%)

Some of the Bouyei students stated that they occupied too much time in preparing CET and TEM that might lead to less daily course study, which is consistent with the previous factor Lack of Preparation. For example:

ST4: ...I find everything we do is just for passing CET, not for anything else...This makes me upset, indeed and I don't know how to overcome it in class.

ST5: ...Many people, including our English teacher, say that it is useful for our future employment-the employers see it as one of the qualifications required. En...so we spend a lot of time on it although we have to do much with normal course study...

ST23: ...TEM is more difficult than CET ... we English majors are devoted too much to such a test and hence have less time to practice our English speaking in class but do more in learning words by heart.

- SI 9.2: Concerns about other tests (5) (20\%)

Other qualification tests are also reported by some interviewees as an aspect of Societal Interferences that brings constraints to them. They stated that they planed to take part in the postgraduate enrollment exams and other qualification exams like the National Computer Test (NCT), the National Lawyer Qualification Test (NLQT), etc. which are useful for future job-seeking. Therefore they spent much time on preparation for them, which also distracts their concentrations away from English class with continuous anxiety. For example:

ST8: ...My parents hope that I will prepare for the postgraduate enrollment exams, so I have to concern about more things other than English learning...

ST22: ... Nowadays, various qualifications are needed for employment. English is not the only useful thing. I don't want to waste time if I cannot succeed in English learning. I will try to pass the NLQT and other qualification exams which are also very useful.

ST12: I will make an effort to pass the postgraduate enrollment exams, so I don't like to spend more time in participating in discussions in English class, since English is really my weakness.

(5) Lack of Confidence (LC) (12) (48\%)

The factor Lack of Confidence includes two main aspects: "being unconfident in communication", and "no confidence even when prepared" (Wei, 2012). They are as follows:

- LC4.1: Being unconfident in communication (6) (24\%)

Some interviewees reported that they were afraid if they could answer the teachers' questions, when not knowing what to say in group discussions and when expressing their ideas in written English. For example:

ST12: ... I feel worried when being called on by the teacher... I am afraid I cannot answer the questions very well.

ST13: ...However, I'm a bit less confident while speaking with the foreign teacher. You know, to speak with a native speaker is a great pressure for me.

ST17: I know my English is so-so, and then always feel unconfident before high ability students in class. I usually dare not participate in discussions.

- LC4.2: No confidence even when prepared (6) (24\%)

"No confidence even when prepared" was what some of the Bouyei students reported as the second aspect of the factor Lack of Confidence. They said that they felt bad in English class even when they were prepared. However, some reported their worries about CET and TEM which were too difficult for them and therefore they lost hope in passing these two sorts of tests although they seemed important for future employment. For example:

ST25: ...I feel bad in English class no matter how I'm prepared...It seems as if I were an idiot in English class, ... although Ifeel much relaxed and confident in other courses.

ST5: ...It's strange that I still feel anxious even when I'm well prepared. Speaking English is so different from speaking Chinese.

ST11: ... I'm always not confident when doing exercises in class because my English foundation is poor and I don't know how to prepare for English class. It's too bad for me....

(6) Fear of Failing English Class (FFEC) (12) (48\%)

The factor Fear of Failing English Class (Wei, 2012) refers mainly to what the students felt worried about whether they would possibly not able to pass in the final exam of the English course, as well as the successive result the learners were not willing to encounter. As reported by some of the interviewees, this factor consists of three aspects including "fear of doing badly in tests", "fear of makeup", and "fear of lengthened study".

- FFEC1.1: Fear of doing badly in tests (5) $(20 \%)$

Some students reported that they tremble when entering the examination room for fear of doing badly (Wei, 2012), get upset when not knowing what to do with some questions in the test. A few key samples were:

ST2: ...I tremble for a while when I enter the examination room until I get absorbed doing the papers.

ST21: ...I tremble for fear of making mistakes in the test, because I'm ambitious to win a satisfactory position in terms of the final scores in class. 
ST8: ...I have the feeling of losing face for not doing so well in recitation in English class.

ST11: ...I cannot learn many new words by heart and always feel terrible in dictations in class, since you know our teacher likes to dictate us nearly every day.

- FFEC1.2: Fear of makeup (4) (16\%)

Besides fear of doing badly in tests, some students reported that they are in much fear of makeup to be done at the beginning of the new term if they cannot pass the final exams. It was reported that they prepared crazily in order not to fail one exam. A few key samples are:

ST6: ...I worry if I will fail in the final exams because I know some classmates have the experience of failing courses and then have to attend additional examinations at the beginning of another term...

ST15: ...That's really a nightmare to me if I am given a makeup...and unfortunately, I have once experienced makeup which still makes me feel bad today when I think of it... This is what I fear most in English learning.

ST17: ...I don't think it necessary to have so many tests...I know tests can push us to make bigger effort, but makeup is what we do not expect and it worries us most and makes us feel tense.

- FFEC1.3: Fear of lengthened study (3) (12\%)

Another aspect is related to students' worry about the worst result of failing the makeup which indicates they have to study the course for another term in order to obtain credits related. A few key samples are:

ST5: ... The regulations of the college manifest that if we cannot pass the makeup, we would loose the credits of the course, which mean that we have to undertake another term's study of the course. I'm a bit worried about it.

ST4: ...To study the course for another term is really a nightmare for each of us. Aha, no one is looking for it. Although it seems not possible for me if I work hard, I still concern it very seriously.

(7) Fear of Losing Face (FLF) (12) (48\%)

The factor Fear of Losing Face refers mainly to what causes the students to worry regarding other's opinions, comments or judgment upon themselves in English learning. It includes two main aspects: "afraid of being laughed in class", and "upset when the teacher corrects my mistakes in public" (Wei, 2012). They are as follows:

- FLF 3.1: Afraid of being laughed in class (7) $\mathbf{( 2 8 \% )}$

Some Bouyei students reported that they feared to be laughed at when speaking with poor pronunciation, or when not knowing what to say or write in class. They reported they worried about if they would lose face when others found their English was poor. For example:

ST8: ...I usually keep silence because I'm afraid of being laughed at by others when not knowing what to say in discussions.

ST10: ...I feel embarrassed when I don't know how to write a sentence correctly on the blackboard (Bb)...At this time I may think my classmates might laugh in their sleeves... What a shame it might be!

ST24: ...Although I can adjust myself, I never expect being laughed by others in class...That is not a good thing anyway.

ST7: ... We learn English which is not needed in everyday communication. So, I'm usually afraid of being laughed at due to my inability to communicate with others when I do not know how to express my mind.

- FLF 3.2: Upset when the teacher corrects my mistakes in public (5) (20\%)

Some Bouyei students reported that they worried when making oral or written mistakes which were right away corrected by the teachers in public, although they thought that correcting mistakes was sometimes necessary (Wei, 2012). They said:

ST18: ...It really worries me when I make mistakes on the Bb and then the teacher corrects them right away... I know it's a need for a correction which is good both for me and for the whole class.

ST5: ...I know if the teacher doesn't correct my mistakes, I will not realize what mistakes I am making. However, being corrected in public is really a shame. ...

ST3: ...I don't think being corrected in class is a big shame, but I'm still in fear of that...and I hope the teacher will give us more encouragement instead.

ST4: ...I worry if my homework is mistaken and causes the teacher' correction in class.

(8) Lack of Preparation (LP) (12) (48\%)

Lack of Preparation was reported by some informants as the factor contributing to their anxiety. This factor consists of two aspects: "not studying so hard as expected" and "difficulty in preparation", which are as follows:

- LP6.1: Not studying so hard as expected (6) (24\%)

Some of the interviewees expressed honestly that they did not study as hard as their English teacher had expected (Wei, 2012), which resulted in inadequate preparation for English class. For example:

ST15: ...I don't care for being asked to the Bb if I am well prepared. ...However, sometimes I'm lazy and do not finish exercises assigned by the teacher.

ST17: ...I don't study as hard as the teacher expects and not so actively do exercises after class. This is the main reason for my anxiety in class.

ST12: ...I can be very anxious when not understanding the teacher speaking too fast, or when I do not prepare as required.

ST15: ...I don't care for being asked to the Bb if I am well prepared. ...However, sometimes I'm lazy and do not finish exercises assigned by the teacher. 


\section{- LP 6.2: Difficulty in preparation (6) (24\%)}

This aspect is related to what they thought to be their FL ability lower than required that hence brings about their inefficient learning and inadequate preparation due to the hardship they encounter. They reported that English learning and other exams were not easy and they tried hard to prepare but achieved very little as a result. For example:

ST5: ... I like English very much, but I'm not so good at it. So when I feel I'm not so well prepared as I have done, I'm afraid the teacher will ask me the questions that I'm unable to answers.

ST25: ...I feel bad in English class no matter how I'm prepared...It seems as if I were an idiot in English class, ... although Ifeel much relaxed and confident in other courses.

ST5: ...It's strange that I still feel anxious even when I'm well prepared. Speaking English is so different from speaking Chinese.

(9) Sense of Inferiority (SOI) (9) (36\%)

Sense of Inferiority (Wei, 2012) in the present study mainly refers to the students' feeling of self-contempt due to unsatisfactory behaviors or performances in classroom activities. It was reported by the Bouyei students as a factor responsible for their anxiety, which includes "unbalanced mentality in face of students better at English" and "feeling of low social status" as follows:

- SOI 7.1: Unbalanced mentality in face of students better at English (4) (16\%)

Some of the interviewees reported that they felt uncomfortable while seeing other classmates answer some questions or speak better English they could not. This was likely to bring them a sense of being hurt in an unbalanced psychological situation that accompanied them in class.

ST17: ...Honestly speaking, I feel uncomfortable when seeing some other classmates able to answer what I cannot, although this facilitates my study in return.

ST8: ...I exactly experience the unbalanced psychological situation-Sometimes, I feel a bit inferior when realizing my language ability is lower than others'.

ST19: ...I am a bit worried when my classmates can speak more fluently than I do...

ST22: ... My self-esteem is too strong. I feel hurt when I am proved lower in ability in class, and sometimes even get puzzled as if I would be too much disappointed at my performance.

- SOI 7.2: Feeling of low social status (5) $(20 \%)$

Some interviewees claimed that they were self-contemptuous as other students did not feel like talking with them in discussions for their poor pronunciation or poor spoken English (Wei, 2012). For example:

ST1: ...I'm not so anxious if other classmates are better at English, but much unhappy when it seems that other classmates do not feel like talking with me in discussions...I think it may be because of my poor pronunciation and grammar. It seems that I'm poor in everything.

ST5: ...I don't feel inferior among the Han students, because there are many other minority students in class. However, I can feel embarrassed when not able to behave so well as others in class.

ST7: ...Actually, I used to be self-inferior to others who came from the urban areas and whose family financial conditions seemed much better than mine. ...However, they do not interfere with my English study when I have made greater progress.

\section{Discussion}

The abovementioned findings reveal that (1) Low FL Ability (LFLA)), (2)Teacher's Problem in Teaching (TPT), (3)Negative Attitudes towards English Class (NAEC), (4)Societal Interferences (SI), and (5)Lack of Confidence (LC) seem to be the most frequently reported categories of the informants' anxiety arousals, followed by (6)Fear of Failing English Class (FFEC), (7)Fear of Losing Face (FLF), (8)Lack of Preparation (LP), and (9)Sense of Inferiority (SOI). The first factor is composed of "fear of doing badly in tests", "fear of makeup", and "fear of lengthened study"; the second, "fear of being laughed in class", and "feeling upset when the teacher corrects my mistakes in public"; the third, "more anxiety in English class than in other classes", "no interest in English class", and "nothing learned in English class"; the forth, "being unconfident in communication", and the fifth, "no confidence even when prepared"; "inability in listening", "inability in speaking", "inability in reading", and "inability in writing"; the sixth, "not studying so hard as expected", and "difficulty in preparation"; the seventh, "unbalanced mentality in face of students better at English", and "feeling of low social status"; the eighth, "unequal treatment", "talking too much in class", "humdrum teaching styles", and "motion inappropriately shown"; and the last, "pressure from CET and TEM, and "concerns about other tests". It is noteworthy that four categories (i.e., the $3^{\text {rd }}$, the $5^{\text {th }}$, the $6^{\text {th }}$, the $8^{\text {th }}$ ) of the anxiety arousals share the same with what were found in the rotated component matrix of factor analysis for the FLCAS which was adapted from Horwitz et al. (1986) and conducted in the present researcher's previous study (Wei, 2012: 75-90), whereas most of the other causal factors are different except for the $7^{\text {th }}$ that is similar to "Fear of Negative Evaluation" defined (Wei, 2012: 75-90).

These results demonstrate that the Bouyei informants felt most anxious about their FL competence which accounts for the first anxiety causal factor category Low FL Ability. The learners also had common problems in their personal traits that might include Lack of Confidence, Fear of Failing English Class, and Fear of Losing Face as they may be classified into a same category, because these factors are closely interrelated with each other by sharing the similar 
collective character, behavioral temperamental emotional, and mental characteristics of a person (McCrae \& Costa, 1997; cited by Wei, 2012). These arousals mean that the Bouyei college students need to alleviate their anxiety by enhancing their self-confidence via the improvement of the FL proficiency (Wei, 2012). As for the Negative Attitudes towards English Class, the learners complained that they have learned very little in EFL class which resulted in their losing interest in it, which further explained why they also complained about Teacher's Problem in Teaching. It seems that they had strong "Filters" of their English input, and it is the teacher's responsibility to give up humdrum, ever-lasting teaching styles by playing their part to help alleviate learners' FL anxiety, including keeping rapport with learners, helping learners develop their sense of involvement, and treating them equally in class, as also claimed by Liu (2006a) and Marwan (2007). Concerning Sense of Inferiority, It is claimed that a young individual who represents an ethnic minority culture in a classroom is likely to have anxiety and then gets very quiet because of ethnic/cultural differences that may cause learners' to sensitively have the feeling of low social status and self-identity (McCroskey, 1980). Since more interaction usually refers to equal teacher-to-student relationship, FL learners may feel worried in face of social or cultural embarrassment and a threat to their social identity (Doughty and Pica, 1986; cited by Wei, 2012). However, the results show that the Bouyei informants did not feel embarrassed among the Han students but had unbalanced mentality when talking with learners better at English. They also had a feeling of low social status as other learners did not feel like communicating with them in pair work due to their poor pronunciation or poor oral ability. These statements were also found supportive to the studies by Zhang et. al. (2003) and Tanveer (2007). Regarding Societal Interferences, the Chinese Bouyei college learners complained a lot about "pressure from CET and TEM" and "concerns about other tests", which distracted their concentrations away from their formal EFL learning in class, since they had to spend much of their precious time being worried about how to pass various tests for certificates as possible qualifications for their future job-seeking. This anxiety arousal is scarcely reported in the literature of EFL classroom anxiety studies, most possibly because it is characteristic of Chinese culture in the so-called examination-oriented education.

\section{CONCLUSION}

In accordance with the analysis of the data which were collected from the semi-structured individual interviews, the Chinese Bouyei college learners mainly reported nine types of anxiety causal factors in EFL classroom, as abbreviated to LFLA, TPT, NAEC, SI, LC, FFEC, FLF, LP, and SOI. Since it's not easy for learners themselves to automatically alleviate their EFL anxiety in class, the language instructors are hence responsible for lessening their FL classroom anxiety by establishing harmonious relationship with learners, giving more equal chances to them to talk, show more and adequate regard to them with various trends of EFL classroom anxiety. It is also necessary for teachers to undertake further self-education for possible accomplishments in EFL teaching in order to receive relative training for the improvement of EFL proficiency, teaching approaches, and all comprehensive abilities to make EFL class interesting. These might concern about the cultivation of instructors' cognition upon the principles of teaching methodology for blended teaching styles, their communicative competence, and, most importantly, their personality traits in an advantageous orientation associated with the eventual effect of language teaching (Wei, 2012). The results in terms of frequency of the reported anxiety arousals also indicate that the effect of "Chicken or Eggs" theory (Hider, 1997, pp. 61-68) that manifests the subtle relationship between learners' poor English proficiency and teachers' incapability in English teaching must be paid much attention to while concerning the educational system in relation to the vast investment with not-so-satisfactory achievements in the domain of EFL education in China.

\section{REFERENCES}

[1] Aida, Y. (1994). Examination of Horwitz, Horwitz, and Cope's construct of foreign language anxiety: The case of students of Japanese . The Modern Language Journal 78, 155-68.

[2] Chapell, M., Blanding, B., Silverstein, M., Takahashi, M., Newman, B., Gubi, A., et al. (2005). Test anxiety and academic performance in undergraduate and graduate students. Journal of Educational Psychology, 97(2), 268-274.

[3] Chen, H. (2002). College students' English learning anxiety and their coping styles. M.A. dissertation, Southwest Normal University,http://www.cnki.net/kcms/detail/Detail.aspx?dbname=CDMDTOTAL\&filename=2002113517.nh\&filetitle=大学生 英语学习.

[4] Chen, M.L (2007). Test anxiety, reading anxiety and reading performance among university English as second language learners. Unpublished M.A. thesis of the Department of Applied English, the College of Applied Languages, the Ming Chuan University, Taiwan, China, 11-58.

[5] Cheng, Y.S, Horwitz, E. K., \& Schallert, D. L. (1999). Language anxiety: Differentiating writing and speaking components. Language Learning, 49 (3), 417-446.

[6] Cheng, Y.S. (2002). Factors associated with foreign language writing anxiety. Foreign Language Annals, 35(6), $647-656$.

[7] Chick, J. K. (1985). The interactional accomplishment of discrimination in South Africa. Language in Society, 14, $299-326$.

[8] Dai, W.D, \& Wang, D. (2002). A survey of English majors' beliefs about language learning. Foreign Language World, 91(5), 24-29.

[9] Dewaele, J. M., Petrides, K. V., \& Furnham, A. (2008). Effects of trait emotional intelligence and sociobiographical variables on communicative anxiety and foreign language anxiety among adult multilinguals: A review and empirical investigation. Language Learning, 58(4), 911-960. 
[10] Dewaele, J.M. (2002). Psychological and sociodemographic correlates of communicative anxiety in L2 and L3 production. The International Journal of Bilingualism, 6, 23-39.

[11] Doughty, C., \& Pica, T. (1986). Information gap tasks: An aid to second language acquisition? TESOL Quarterly, 20, $305-325$.

[12] Gobel, P., \& Matsuda, S. (2003) Anxiety and predictors of performance in the foreign language classroom, Science Direct Journal, 32 (1), 21-36.

[13] Gregersen, T. S. (2005). Nonverbal cues: Clues to the detection of foreign language anxiety. Foreign Language Annals, 38 (3), $388-400$.

[14] Hider, P. (1997). Chicken or Eggs. The Journal of Qiannan Teachers College for Nationalities, (2), 61-68.

[15] Horwitz, E. K. (Ed.) (2001). Language anxiety and achievement. Annual Review of Applied Linguistics, 21, 112-126.

[16] Horwitz, E.K., Horwitz, M, B \& Cope, J. (1986). Foreign language classroom anxiety. Modern Language Journal 70: 125-132.

[17] Huang, H. (2008). University EFL students' and their teachers' preferences for In-class activities and their Relationships to the Students' Foreign Language Anxiety. Unpublished M.A. thesis of Providence University, Taiwan, China, 58-69.

[18] Jackson, J. (2002). Reticence in second language case discussions: Anxiety and aspirations. System, 30(1), 65-84.

[19] Krashen, S. D. (1982). Principles and Practice in Second Language Learning. New York: Pengamon.

[20] Laine, E.J. (1987). Affective factors in foreign language learning and teaching: A study of the "Filter", Jyvaskyla Cross-Language Studies'. Accessed From: http://www.eric.ed.gov/ERICDocs/data/ericdocs2sql/content_storage_01/0000019b/80/1c/7c/15.pdf(02/08/07-28/08/07).

[21] Leary, M. R. (1983). A brief version of the fear of negative evaluation scale. Personality and Social Psychology Bulletin 9(3): 371-375.

[22] Liu, M (2006a). Anxiety in EFL classrooms: Causes and consequences. TESL Reporter, 39(1): 13-32.

[23] Liu, M (2006b). Anxiety in Chinese EFL students at different proficiency levels. System, 34(3): 301-316.

[24] Liu, M., Zhang, W., \& Lu, Z. (2010). Reticence and anxiety in Chinese university ESP poetry class: A case study. Journal of Language and Culture, 2(2), 20-33.

[25] MacIntyre, P. D., \& Gardner, R. C. (1991). Investigating language class anxiety using the focused essay technique. The Modern Language Journal, 75 (3), 296-313.

[26] Marwan, A. (2007). Investigating students' foreign language anxiety. Malaysian Journal of ELT Research, 3, 37-55.

[27] Matsuda, S. \& Gobel, P.(2004) Anxiety and predictors of performance in the foreign language classroom. System, 32, 21-36.

[28] McCrae, R. R., \& Costa Jr, P. T. (1997). Personality trait structure as a human universal. American psychologist, $52(5), 509$.

[29] McCroskey, J. C. (1980): Quiet children in the classroom: On helping not hurting. Communication Education, $29,239-244$.

[30] Ohata, K. (2005). Language anxiety from the teacher's perspective: Interviews with seven experienced ESL/EFL teachers. Journal of Language and Learning, Vol. 3 (1), 133-155

[31] Onwuegbuzie, A., Bailey, P., Christine, E. and Daley. (1999). Factors associated with foreign language anxiety. Applied Socio Linguistics, 20 (2), 218-239.

[32] Paunch, K. (2005). Introduction to social research: Quantitative and qualitative approaches ( $2^{\text {nd }}$ ed.). London: SAGE.

[33] Rubio, F. (Ed.) (2007). Self-esteem and Foreign Language Learning. Newcastle: Cambridge Scholars Publishing, 2-206.

[34] Spielberger, D. (1972). Anxiety: Current Trends in Theory and Research, New York: Academic Press.

[35] Strauss, A., \& Corbin, J. (1998). Basic of Qualitative Research: Techniques and Procedures for Developing Ground Theory (2 $2^{\text {nd }}$ ed.). Thousand Oaks, California; SAGE.

[36] Tan, Y. (2009). The relationship between anxiety and college students' achievements: A survey of non-English majors. Journal of Suzhou University of Science and Technology (Social Sciences), 26(2), 142-144.

[37] Tanveer, M. (2007). Investigation of the factors that cause language anxiety for ESL/EFL learners in learning speaking skills and the influence it casts on communication in the target language. Thesis of Educational Studies, Faculty of Education, University of Glasgow, 10-53.

[38] Tasee, P. (2009). Factors affecting the English major students' anxiety about speaking English. A Ph.D. thesis, Suranaree University of Technology, Nakhon Ratchasima, Thailand, academic year 2009, 63-128.

[39] Tsui, ABM. (1996). Reticence and anxiety in second language learning. In K. M. Bailey \& D. Nunan (eds.). Voices from the language classroom. Cambridge: Cambridge University Press, 145-167. umn.edu/NCEO/Online Pubs/Tech44/

[40] Wei, J.H. (2012). The Chinese Bouyei College Students' Classroom Anxiety in Foreign Language Learning: A Survey Study, International Journal of English Linguistics, 2(2), 75-90.

[41] Wei, J.H. (2013). A Study via Interviews of the Chinese Bouyei College Learners' EFL Classroom Anxiety Coping Strategies, Theory and Practice in Language Studies,3(4), 660-668.

[42] Wang, W. (2009). The relationship among self-esteem, situational anxiety and English proficiency: A quantitative investigation into college English learners. Teaching English in China-CELEA Journal, 32 (6), 118-128.

[43] Yamashiro, A.D., \& McLaughlin, J. (2001). Relationships among attitudes, motivation, anxiety, and English language proficiency in Japanese college students. In: P. Robinson, M. Sawyer \& S. Ross (Eds.), Second language acquisition research in Japan: JALT Applied Materials Series, Vol. 4 (pp. 19-33). Tokyo: Japan Association of Language Teachers Press.

[44] Young, D. J. (1991). Creating a low-anxiety classroom environment: What does language anxiety research suggest? Modern Language Journal, 75(4), 426-439.

[45] Zhang, A. (2009). A survey of primary school English teachers' accomplishments in the ethnic rural areas. Journal of the Qiannan Teachers College for Ethnic Groups (2), 45-48.

[46] Zhang, Q.F, Cun, J.P. \& Yu, H. B. (2003). A study of the psychological unbalance among the ethnic minority students. China Experts Web. http://www.inaexpertsweb.net/yxlw02/yyxx llw07.htm(Access:11/03/2011). 
Jianhua Wei was born in Sandu, China in 1964. He received his M.A. degree in English Language Studies from the Suranaree University of Technology, Thailand in 2012.

$\mathrm{He}$ is at present a professor in the School of Foreign Languages, the Guangdong Institute of Petrochemical Industry, Maoming, China. His research interests include SLA, teaching methodology, and translation theory and practice.

Prof. Wei is a member of the Translators Association of China. 